\title{
Mulemba
}

Revista Angolana de Ciências Sociais

4 (8) | 2014

Globalização, gestão e dinâmicas de desenvolvimento regional e local

\section{Para uma perspectiva sobre a prática das Ciências Sociais: uma leitura de Charles C. Ragin, Constructing social research: the unity and diversity of method}

Cesaltina Abreu

\section{OpenEdition}

\section{Journals}

Edição electrónica

URL: http://journals.openedition.org/mulemba/447

DOI: $10.4000 /$ mulemba.447

ISSN: 2520-0305

\section{Editora}

Edições Pedago

Edição impressa

Data de publição: 1 novembro 2014

Paginação: 525-556

ISSN: 2182-6471

Refêrencia eletrónica

Cesaltina Abreu, «Para uma perspectiva sobre a prática das Ciências Sociais: uma leitura de Charles C. Ragin, Constructing social research: the unity and diversity of method», Mulemba [Online], 4 (8) | 2014, posto online no dia 23 novembro 2016, consultado o 26 janeiro 2021. URL: http:// journals.openedition.org/mulemba/447 ; DOI: https://doi.org/10.4000/mulemba.447

Este documento foi criado de forma automática no dia 26 janeiro 2021.

Tous droits réservés 


\title{
Para uma perspectiva sobre a prática das Ciências Sociais: uma leitura de Charles $\mathrm{C}$. Ragin, Constructing social research: the unity and diversity of method
}

\author{
Cesaltina Abreu
}

\section{NOTA DO AUTOR}

Cf. RAGIN Charles C., Constructing social research: the unity and diversity of method.

Thousand Oaks (CA), Pine Forge Press, 1994, 208p. [«Sociology for a new century»].

1 A obra Constructing social research: the unity and the diversity of method, do sociólogo norte-americano Charles C. Ragin, compreende duas partes: a Parte I, desdobra o tema «Elementos de pesquisa social» em 3 capítulos: «O que é pesquisa social», «Os objectivos da pesquisa social» e «O processo da pesquisa social: ideias e evidências». Na Parte II, o tema «Estratégias da pesquisa social» é abordado pelo autor também em 3 capítulos: «Métodos qualitativos para as comunalidades», «Métodos comparativos para a diversidade», e «Métodos quantitativos para a relação entre variáveis (covariação)». Para além de uma «Nota do Editor» e do «Prefácio», o livro apresenta um «Post-Scriptum» e um «Apêndice sobre cálculo de coeficientes de co-relação».

2 Na «Nota do Editor» é destacado o objectivo a alcançar com a selecção dos livros apresentados nesta série, como sendo o de preparar os estudantes e o público mais esclarecido para um mundo que mudou radicalmente. Destaca que as Ciências Sociais alcançaram uma orientação mais ampla e um interesse crescente numa pesquisa que seja comparativa, histórica e transnacional. Esta mudança na orientação fica a dever-se ao facto de que os cientistas sociais estão mais sensíveis a processos e tendências 
globais, o que os torna menos isolados; por outro lado, é visível um esforço em conectar a Sociologia com as experiências e preocupações do público mais esclarecido.

3 A obra apresenta uma perspectiva sobre a prática das Ciências Sociais; a comparação da pesquisa em Ciências Sociais com outras formas de construir representações da vida social, como o faz o jornalismo por exemplo, permite captar a diferença daquela em relação às outras formas de representação, uma vez que nela está implícito um diálogo entre ideias e evidências, resultando em representações científicas da vida social, fortemente alicerçadas na teoria e nos dados empíricos.

Charles Ragin elabora este argumento através do recurso a uma série de exemplos e mostra importantes continuidades nas três principais formas da pesquisa social: a qualitativa sobre os aspectos comuns, a comparativa sobre a diversidade e a quantitativa sobre as relações entre variáveis. Estas três estratégias fornecem uma fundação sólida para o estudo de todos os fenómenos sociais, do exame das complexidades da vida no dia-a-dia à investigação sobre o poder dos processos transnacionais.

\section{Prefácio}

5 Salientando os extremos em que habitualmente os livros sobre pesquisa social podem ser classificados, passando a ideia de que a pesquisa social é uma mistura confusa de actividades desconectadas, o autor refere que em alguns casos ela é apresentada com algo muito próximo à pesquisa em ciências exactas (física, por exemplo), enquanto que noutros, aparece um traço mais humano.

6 Considerando o seu livro como uma alternativa, o autor afirma que ele oferece uma visão mais ampla e integrada da pesquisa social, procurando responder à pergunta: o que é pesquisa social?, recorrendo a diversos exemplos que ilustram o pensamento actual acerca das grandes questões em metodologia das ciências sociais e da lógica da análise. Ele lembra que é mais fácil assumir que se sabe o significado de algo do que explicá-lo ou defini-lo, o que se aplica ao termo pesquisa social.

o seu principal objectivo é o de demonstrar unidade dentro da diversidade de actividades que compõem a pesquisa social de modo a dar-lhe um sentido de abrangência. Apesar da diversidade de objectos das pesquisas - dados de censos de centenas de milhares de pessoas ou o estudo em profundidade de uma pessoa, análise sobre questões da rotina da vida actual ou estudos sobre a vida em séculos passados -, o Autor afirma existir uma unidade nesta diversidade porque todas elas são formas de representação da vida social. Por isso, usa esta ideia como ponto de partida e procura demonstrar que todos os pesquisadores estão engajados num diálogo entre ideias (teoria) e evidências (dados) quando constroem as suas representações.

8 A sua ênfase distingue-se das típicas representações das Ciências Sociais que opõem a análise quantitativa à qualitativa, ao assumir que todos os pesquisadores trabalham tanto com palavras quanto com números. Considera que a diferença entre pesquisa quantitativa e pesquisa qualitativa não se pode equacionar em termos de números versus palavras, mas sim no foco da pesquisa: enquanto a primeira se concentra nos laços entre um número menor de atributos em muitos casos, a segunda tem como foco os laços entre um número maior de atributos em relativamente poucos casos, ou seja, 
trata-se de uma questão de orientação da pesquisa, uma vez que ambas envolvem uma interacção sistemática entre ideias e evidências.

9 Na Parte I do livro, Ragin procura oferecer diversas respostas para a pergunta acima apresentada, introduzindo questões essenciais para as Ciências Sociais, como o seu objecto e a sua metodologia e ressaltando as características distintivas entre as representações sociais produzidas pelos pesquisadores e as produzidas por outros profissionais igualmente envolvidos com outros aspectos da vida social, como os jornalistas.

$\mathrm{Na}$ parte II são analisadas as duas estratégias mais habituais - quantitativa e qualitativa -, e um terceiro tipo de pesquisa social, a abordagem comparativa, que em muitos aspectos se situa entre as duas anteriores, mas cujo papel é o de ajudar a quebrar a barreira existente entre elas. A introdução desta terceira abordagem permite compreender a unidade na pesquisa em Ciências Sociais: tal como a pesquisa qualitativa, a pesquisa comparada dá bastante atenção aos casos individuais e, tal como a pesquisa quantitativa, concentra a sua atenção nas diferenças entre os casos, procurando dar sentido a tais diferenças.

11 Embora estas três abordagens sejam distintas entre si, serão melhor compreendidas como diferentes maneiras de conduzir um diálogo social científico entre ideias e evidências. Em cada abordagem, são necessárias ideias claras para a construção do processo de representações porque elas podem ajudar os pesquisadores a organizar e dar sentido ao grande conjunto de evidências envolvidos em qualquer investigação social científica.

\section{Capítulo I - 0 que é pesquisa social?}

12 O autor passa em revista diversas maneiras de responder a essa questão, chamando a atenção para as três respostas convencionais a esta distinção: o seu objectivo central, ou seja uma outra maneira de compreender a sociedade, o argumento de que nela é usada uma linguagem específica para falar de sociedade e, ainda, que ela recorre a métodos científicos para o fazer. Nesta abordagem, ele procura identificar as semelhanças e distinguir as diferenças existentes entre a abordagem das Ciências Sociais e as outras abordagens também preocupadas em traçar perfis da sociedade.

Começando pelo conteúdo de «sociedade» enquanto objecto da pesquisa social e lembrando que tanto é usado no sentido mais amplo do conjunto de pessoas que constituem um estado-nação ou no sentido mais estrito das relações formais de interacção humana, o Autor lembra questões como o tamanho e o tipo de organização das interacções humanas que são elementos importantes mas que não podem ser dissociados dos respectivos significados históricos e culturais, para se conseguir uma caracterização mais adequada. Isto significa que aspectos importantes que interessam aos cientistas sociais, não podem ser abordados como características gerais das interacções ou organizações humanas.

Relativamente à questão "o que é Sociedade?», o autor sugere uma abordagem do tipo sociedade = vida social, ou seja, pessoas fazendo coisas em conjunto. Muitas vezes são histórias ou outros detalhes de vida, momentos, e há cientistas sociais estudando tanto uns quanto os outros. 
15 Por outro lado, a acção implica a «não-acção», ou seja, a recusa ou acto intencional de não fazer algo por discordância e implica, também, a «apatia» e/ou o «desafio» que pressupõem recusa. Todos estes tipos de acção, incluindo o «suicídio» são, na perspectiva de Ragin, inerentemente sociais: têm causas, consequências e significados sociais.

argumentação é usada para demonstrar que os cientistas sociais têm um amplo e diverso campo de acção e que esta definição de sociedade pouco contribui para distinguir pesquisa social de outras formas de representar a sociedade.

17 Relativamente ao segundo tipo de resposta, aquela que identifica uma linguagem específica na pesquisa social, ele lembra que este argumento se baseia no facto de os cientistas sociais vulgarmente usarem a relação entre variáveis, as medidas das variáveis, e defende que a linguagem das variáveis e respectivas relações permite uma descrição directa e sumária dos padrões gerais de correspondência entre duas categorias de análise.

18 Contudo, Ragin contrapõe exemplificando que muitos cientistas sociais não usam este tipo de linguagem preferindo outra, mais descritiva, que recorre à observação sistemática e visa tornar conhecidos os acontecimentos. Entretanto, outros profissionais, como jornalistas e políticos, são utilizadores comuns desta linguagem para avaliar tendências sociais ou abordar os problemas da sociedade e respectivas soluções. Para Ragin, existem demasiadas evidências do uso corrente desta linguagem no dia-a-dia, por pessoas comuns referindo-se a aspectos comuns das suas vidas.

19 A terceira resposta convencional sobre a pesquisa social baseia-se na ideia de que ela segue um método científico, enquanto outras formas de representação da sociedade, como documentários e reportagens, não fazem recurso a ele. Esta resposta busca, de alguma forma, «legitimar» a pesquisa social argumentando que, tal como sucede nas ciências exactas, as suas conclusões se baseiam em experiências, muitas vezes realizadas em laboratório (sob condições controladas). o método científico consiste na formulação e teste de hipóteses, a partir do conhecimento dos fenómenos que se pretende analisar e do conhecimento existente e ao alcance do pesquisador na área ou matéria em discussão, ou a partir de estudos e trabalhos anteriores de outros cientistas, sob a forma de relações entre duas variáveis de um conjunto de categorias ou casos de análise. Ou seja, através de um processo de «dedução» sobre determinada realidade ou assunto, são extraídas proposições ou expectativas.

20 Após a formulação da(s) hipótese(s), o cientista recorre a diversos meios para obter os dados relevantes para a confirmação ou negação da hipótese em análise: através de entrevistas, questionários ou colecta de opiniões. A análise estatística dos dados recorre a diversos testes de medição, comparação e variação. Os resultados da análise podem levar a sugerir a alteração das ideias ou pressupostos iniciais, ou seja, podem indicar a necessidade de reformulação das ideias que serviram de ponto de partida. Este processo designa-se «indução» e permite estender, melhorar ou reformular as ideias existentes. Segundo Ragin, a dedução parte de ideias gerais e aplica-as à evidência, enquanto que a indução parte das evidências e avalia as suas implicações nas ideias gerais.

21 Assim, os dados colhidos confirmam ou rejeitam a hipótese formulada e, segundo Ragin, o método científico funciona melhor quando podem ser usadas teorias diferentes para decidir entre as hipóteses em análise: quando hipóteses diametralmente opostas são deduzidas a partir de duas ou mais teorias, a análise dos dados funciona como um 
teste decisivo para os argumentos que se opõem, pois se as teorias deram origem a argumentos que se contradizem, os dados ou confirmam uma ou outra.

Embora muitos pesquisadores utilizem este método de análise para testar as suas hipóteses e progredir nos seus estudos, muitos outros valorizam a informação que obtêm junto de grupos marginalizados (pobres, prostitutas, etc), sem voz na sociedade, para obtenção de elementos que lhes permitam construir as suas representações sociais, apesar das dificuldades em contrapôr os seus resultados às ideias e teorias existentes sobre a área ou assunto.

Entretanto, outros pesquisadores confrontam-se com problemas relacionados com a formulação, muitas vezes imprecisa ou mesmo ambígua, das Ciências Sociais devido às contingências presentes na vida social. Por muito que procurem seguir a preceito o método científico, são muitas vezes confrontados com argumentos contraditórios; outras vezes, os resultados da análise dos dados colectados colocam-nos perante a evidência de que seus postulados estavam errados, o que nem sempre é fácil de aceitar. Nestes casos, é frequente a busca de imprecisões nos dados devido à dificuldade em medir, com precisão, os fenómenos ou práticas sociais. Por isso, muitos pesquisadores lançam mão de diversas estratégias que lhes permitam melhor fundamentar as representações da vida social que pretendem construir, apresentando-as como tendências e não como características definidas da estrutura social.

24 As novelas, filmes, documentários fotográficos ou reportagens, também têm como objectivo a análise da interacção entre as pessoas e também são representações da vida social. Contudo, contrariamente aos pesquisadores sociais que apresentam claramente as suas próprias conclusões incorporadas na interpretação das evidências usadas na representação, as representações produzidas pelo cinema, por exemplo, são bem mais informativas do que opinativas, evitando apresentar interpretações e deixando aos espectadores a tarefa de interpretarem e concluírem acerca da representação que lhes foi apresentada. A ficção pode melhor recriar uma determinada situação pelo cuidado em recapturar o verdadeiro carácter da situação que se pretende representar, recorrendo a situações verdadeiras, actuais, que são montadas num quadro de ficção fabricado pelo autor. Nestes dois últimos casos, apesar das representações se basearem na vida social, elas raramente se fundamentam em pesquisa social. As primeiras são melhor fundamentadas e mais condensadas do que as apresentadas nas reportagens e menos processadas do que as construídas pela ficção.

Entretanto algumas similitudes existem entre as pesquisas sociais e as representações jornalísticas: em ambos os casos os objectos das representações são questões sociais relevantes. Os jornalistas também recolhem muita informação sobre a qual terão de decidir quanto à sua relevância para o assunto em análise, procurando identificar os aspectos mais pertinentes, num processo que vai permitindo focalizar cada vez mais o assunto, seleccionando a informação que o qualifique e o realce. Quando a estória está montada, muita da informação colectada foi abandonada, o que também acontece com a pesquisa social. De igual modo, procuram precaver-se em relação a pistas falsas que os afastem das evidências necessárias à análise do seu tema, bem como procuram fugir de influências, estereótipos ou preconceitos que possam mascarar o resultado do seu trabalho. Um outro aspecto comum é que muitos entrevistados respondem o que acham «o desejado» pelo jornalista ou pesquisador, o que pode distorcer as evidências e conduzir a resultados não adequados. 
26 Do enfrentamento destes problemas surgem, a obsessão pela verdade dos factos no jornalismo, e a necessidade de validade dos elementos recolhidos para os pesquisadores. Como têm de recolher informações antes de produzirem representações, os pontos de partida são muito importantes e podem determinar a sequência do trabalho, daí a importância das ligações e dos momentos para a construção das representações, as quais resultam do diálogo, permanente, entre as ideias do pesquisador ou jornalista e as evidências que vai colectando.

As diferenças entre reportagens e pesquisas sociais podem começar a desenhar-se a partir da definição dos respectivos públicos-alvo: as pesquisas, para além das audiências das reportagens, contam com a componente «mundo científico», o que leva os pesquisadores a incluírem nos seus relatórios muitos aspectos técnicos especialmente endereçados à audiência composta por seus pares. E isto porque existem mecanismos de controlo de qualidade dos trabalhos produzidos por membros da classe, o peer reviewing. Neste aspecto, seria interessante perguntar ao autor se nas outras profissões, nomeadamente no jornalismo, isso também não acontece. Mas a necessidade de aceitação e validação pela comunidade científica do seu trabalho, leva os pesquisadores a seguirem os termos de referência para uma pesquisa social que compreendem: seleccionar objectos de análise socialmente relevantes e que também o sejam para a teoria social; sejam baseados na recolha de inúmeras evidências e resultem de alguma forma de análise sistemática. 0 preenchimento destes 4 quesitos dá mais fundamento, em termos de ideias e evidências, às pesquisas sociais e às representações por elas produzidas, o que as torna mais importantes aos olhos da comunidade científica.

28 As questões são seleccionadas para estudo não apenas pelo seu interesse em si, mas porque os pesquisadores acham que elas importam para a explicação da vida social actual ou porque são importantes para esclarecer processos históricos com consequências nas sociedades actuais, como é o caso da escravatura.

29 Por outro lado, os pesquisadores relacionam o seu trabalho com a teoria social, a qual serve como base para a formulação das hipóteses de pesquisa e que pode sair reforçada, ou não, pelo resultado dessa pesquisa: uma vez que esta faz uso de evidências para formular novas ideias pode influenciar mudanças nas ideias existentes e, por via disso, induzir mudanças na abordagem teórica que lhe serviu de ponto de partida. Esta é uma característica distintiva da pesquisa social em relação a outras representações.

\section{Capítulo 2 - Os objectivos da pesquisa social}

30 Para o Autor são sete: 1) identificar padrões gerais e relações; 2) testar e refinar teorias; 3) fazer previsões; 4) interpretar fenómenos importantes do ponto de vista cultural e histórico; 5) explorar a diversidade; 6) dar voz; e 7) avançar com novas teorias.

31 Devido a tão variados objectivos, a pesquisa social tem de lançar mão de diversas estratégias, estabelecendo-se como uma relação entre objectivos da pesquisa e os métodos que deverá seguir: quantitativo, comparativo e qualitativo.

32 Relembrado que o foco das pesquisas sociais são questões relevantes para a sociedade, o Autor considera que essa importância advém dos eventuais resultados para a sociedade do conhecimento de padrões gerais de comportamento das pessoas e dos fenómenos com que elas têm de conviver. O seu conhecimento permite a tomada de medidas, através de políticas públicas, tendentes a corrigir, melhorar ou diversificar tais padrões 
gerais; por outro lado, dada a necessidade de legitimação das Ciências Sociais e dos seus métodos perante a sociedade, o trabalho sobre padrões gerais aproxima-as das ciências exatas, tornando os seus resultados mais aceitáveis como dados científicos e não como exercícios de filosofia ou ideologia política.

Ragin considera que o estado de subdesenvolvimento geral do conhecimento científico nem sempre permite saber que padrões são típicos e quais os atípicos; para pesquisar padrões ou tendências gerais, importa, portanto, trabalhar com um grande número de casos comparáveis.

34 A importância destes padrões gerais relaciona-se também com o segundo objectivo, ou seja, o de testar e refinar teorias existentes: por eles afectarem muita gente, são importantes para a teoria social. Considerando que existe um potencial ilimitado de novas ideias a partir de combinações das ideias existentes, produzindo novas possibilidades, dentro e fora das Ciências Sociais, que melhor ajudem a compreender a relação entre fenómenos sociais aparentemente não conectados e, por via disso, encontrar soluções para problemas que afligem a sociedade. Por isso, um dos objectivos das pesquisas sociais é testar as teorias existentes para poder melhora-las e aumentar o conhecimento socialmente disponível a partir do qual possam ser deduzidas soluções.

Se as hipóteses formuladas a partir das teorias existentes podem considerar-se «previsões» de que um dado resultado se produza sob determinadas condições, os resultados das pesquisas são igualmente previsões: a ocorrência de relações entre variáveis ou fenómenos em análise produzirá, com razoável margem de erro, um determinado resultado ou tendência para a ocorrência de determinada situação, seja ela derivada da análise actual ou de momentos históricos. A acumulação de conhecimento e dos resultados esperados permite a antecipação na tomada de medidas que as minimizem, as potenciem ou as anulem. Neste ponto, Ragin chama a atenção para o facto de que nem sempre as previsões e a compreensão que delas tem a sociedade andam de mãos dadas, dando para tal o exemplo das pesquisas sobre drogas: parece mais fácil prever o comportamento das taxas de crescimento de novos usuários de drogas do que compreender as razões que levam a isso. Reconhecendo que nenhuma ciência pode prever o momento de determinado fenómeno social ou acontecimento natural, específicos, Ragin destaca o papel das pesquisas sociais para aumentar e melhorar a capacidade de formular previsões e de estudar questões histórica e culturalmente relevantes, pelo que, parece importante manter, a par dos estudos sobre padrões gerais, outros sobre questões mais específicas, para responder às interrogações da sociedade.

36 A exploração da diversidade responde a esta necessidade de conhecer com maior profundidade a diversidade em que vivemos. Isto não significa ignorar os padrões gerais, uma vez que o pesquisador os usa para comparar os resultados obtidos nos seus estudos sobre questões mais específicas, mas que complementam o quadro fornecido pelos padrões gerais, enriquecendo-o. A este propósito, Ragin lembra que as pessoas parecem valorizar mais a biodiversidade do que a sociodiversidade, que os antropólogos consideram em acelerado processo de perda de formas de vida num processo de globalização que parece tender para a criação (imposição) da cultura ocidental. Para ele, contudo, essa sociodiversidade ainda é considerável, mesmo nos países do centro do sistema capitalista mundial, o que tem levado a que muitos cientistas sociais escolham um caso novo, para o tornar conhecido. 
37 Este «tornar conhecidas outras formas de vida» permite dar voz a quem não a teve até então, ou seja, para além de acrescentar conhecimento e alargar os horizontes actuais, permite dar visibilidade a grupos marginalizados na sociedade através das suas estórias de vida. Como resultado, a sua integração como novos grupos, com os seus valores e as suas formas de estar na vida, uma vez que os estudos realizados acabam demonstrando a existência de aspectos comuns ao comportamento «aceite» na sociedade, ressaltandose a diferença e as razões que levaram à «ausência de voz» desses grupos. Nestas circunstâncias importa a atitude do pesquisador, procurando interpretar a situação pelos olhos do grupo que pretende analisar, a sua visão de mundo e o seu papel na sociedade; desta forma, os resultados obtidos poderão tornar-se muito úteis para a criação de condições de integração social.

38 A abertura de perspectivas que novas descobertas trazem para o conhecimento, permitindo novas formulações das teorias de forma a abarcarem novas ideias resultantes de novas evidências. O desenvolvimento de novas ideias e novos conceitos resultantes de estudos detalhados da exploração da diversidade, desafia o pensamento convencional e questiona as teorias existentes, podendo conduzir a novas tentativas de explicação, mais amplas e mais precisas. Neste sentido, Ragin introduz o termo "retrodução», ou seja, a interacção entre indução (as ideias das quais se parte) e a dedução (as ideias que se extraem), na medida em que pesquisa é, tipicamente, um diálogo entre ideias e evidências e as teorias sempre saem reforçadas dos testes aos quais são submetidas, mesmo quando estes, de alguma forma, as põem em causa.

Estabelecendo um laço entre objectivos e estratégias, Ragin chama a atenção para as tensões existentes entre objectivos, algumas teóricas, como a visão clássica que considera uma violação a introdução de novas ideias e o teste de teorias no mesmo estudo - os dados que dão origem a uma teoria não podem ser usados para a testar embora a maioria seja de natureza prática, ou seja, por dificultarem ao pesquisador o alcance dos objectivos a que se propôs se a pesquisa envolve o estudo de padrões gerais e, ao mesmo tempo, a análise específica de uma dada característica. Considerando que os dois tipos de estudo são importantes para a compreensão da complexidade da maioria das situações sociais, estas dificuldades podem ser contornadas através do uso de estratégias que permitem acomodar a multiplicidade e a competição entre si dos objectivos da pesquisa. O emparelhamento de métodos com objectivos: métodos qualitativos para a análise pormenorizada de aspectos comuns em relativamente poucos casos, métodos comparativos para a análise compreensiva da diversidade num número moderado de casos, e métodos quantitativos para analisar a co-variação de algumas, poucas, características, em muitos casos.

Numa outra perspectiva, trata-se de recorrer a abordagens intensivas (análise qualitativa), compreensivas (método comparativo) ou extensivas (método quantitativo). A escolha entre focalizar em casos como «todos», em variáveis ou em situações intermediárias das anteriores depende dos objectivos a alcançar com a realização da pesquisa, mas também das capacidades e das energias disponíveis, do trabalho individual ou em equipas, uma vez que o mais importante é como a informação colectada é tratada e a sua relevância para o objectivo em vista. De forma geral, os objectivos 1, 2 e 3 são melhor alcançados através do recurso a métodos quantitativos; os objectivos 4, 6 e 7 pelo recurso a métodos qualitativos, e o objectivo 5 pela análise comparativa; o objectivo 7 requer análise comparativa complementar para a comprovação da necessidade de introduzir novas ideias. 
41 Segundo Ragin, a natureza social da pesquisa social é particularmente bem explicitada nos objectivos 4,5 e 6 , porque ao mesmo tempo que são fontes de criticismo - na medida em que os seus resultados influenciam a maneira de ver «a», e pensar "da», sociedade - muitas das suas evidências e ideias têm o poder de introduzir mudanças nem sempre desejadas por todos os estratos da sociedade. Pelo mesmo motivo, torna-se difícil aceitar que os pesquisadores sociais não sejam influenciados pelo «peso» das ideias estabelecidas, nem atraídos pelo fascínio das ideias novas.

\section{Capítulo 3 - 0 processo da pesquisa social: ideias e evidências}

Considerando que a pesquisa social é um diálogo entre ideias e evidências, o capítulo analisa como se estrutura este diálogo e como ele é conduzido, ou seja, como as ideias formatam a compreensão das evidências e como estas afectam as ideias.

O mais importante neste diálogo é a análise (desdobramento nas partes constituintes) dos fenómenos (factos ou eventos sociais), e a síntese das evidências - juntando as partes analisadas para compreender o seu sentido. Pela síntese constrói-se um conjunto harmonioso, estabelecendo relações que podem conduzir a novas perspectivas das evidências que buscam compreender o todo em análise: ela consiste num processo de formação de imagens do assunto em estudo, baseadas nas evidências. Na pesquisa social, as representações da vida social emergem das interacções entre as estruturas analíticas (que derivam das ideias) e as imagens (que derivam das evidências). 0 importante é compreender como se processa o diálogo entre as estruturas analíticas (que articulam ideias) e as imagens (que consistem em representações da vida social baseadas em evidências). A primeira parte do capítulo introduz os quatro blocos básicos da construção da pesquisa social: ideias, estruturas analíticas, evidências e imagens; a segunda parte do capítulo analisa as diferenças nas interacções de imagens e estruturas analíticas nas três estratégias mais comuns em pesquisa social.

O modelo da pesquisa social apresentado pelo autor tem na base as evidências ou dados usados para estudar em detalhe um pequeno número de casos (como sucede nos estudos qualitativos dos aspectos comuns), uma moderada quantidade de informação sobre um número intermediário de casos (como acontece nos estudos comparados de diversidade) ou uma quantidade limitada de informação relativa a inúmeros casos (como nos estudos quantitativos de co-variação). No topo do modelo encontram-se as ideias - ou a teoria social - , a partir das quais os pesquisadores constroem as suas hipóteses e às quais recorrem durante a pesquisa para compreender as questões em estudo. As estruturas analíticas estão presentes na vida do dia-a-dia e nem sempre se apresentam articuladas ou são objecto de contestação, ao contrário das estruturas analíticas que orientam a pesquisa social, as quais são cuidadosamente especificadas e caracterizam o fenómeno em estudo, pois o seu papel é permitir ao pesquisador ver os fenómenos sociais de ângulos que reforcem a sua importância para a teoria social.

As imagens são construídas a partir das evidências: através da síntese destas, os pesquisadores juntam as diversas partes ou elementos dos seus objectos de estudo para criar representações mais acabadas a partir de alguma ideia de como essas partes se relacionam entre si. As imagens iniciais apontam os caminhos da colecta de novos dados, mais evidências, e de um progressivo refinamento da imagem, num processo de 
análise que faz recurso às estruturas analíticas para a articulação das ideias. As evidências (dados) colectadas podem, ou não, confirmar as imagens iniciais. No caso negativo, podem requerer o auxílio de outras estruturas analíticas a que não se tinha recorrido ou a criação de novas. Todo este processo de refinamento das imagens e de ajustamento das estruturas analíticas faz parte do relatório que apresenta os resultados do estudo.

46 As ideias que resistem ao escrutínio constituem o stock de conhecimento que passa de geração em geração; em Ciências Sociais este conhecimento abstracto acerca da vida social é chamado de teoria social, que oferece uma fonte inesgotável não apenas de construção de inúmeras hipóteses de estudo, mas também de reservatório de ideias para a compreensão dos fenómenos da vida social, contribuindo para a produção de novas ideias.

47 As estruturas analíticas constituem os diversos caminhos para a interpretação das ideias e fazem parte do quotidiano das pessoas que, implicitamente, fazem um permanente recurso a elas para compreender os fenómenos e tomar decisões. Elas são usadas para a determinação das categorias de análise e fornecem as ferramentas conceptuais para diferenciar os fenómenos dentro de uma mesma categoria, qualificando-os. Resultando da articulação de ideias disponíveis no stock de conhecimento de uma pessoa, o seu uso será mais eficaz se esse stock de informação é vasto, ou seja, em princípio mais conhecimento dará origem a um maior número de estruturas analíticas. Por outro lado, quanto mais aberta a mente à diversidade maior a possibilidade de fazer um uso adequado das estruturas analíticas para compreender a diferença, através da interpretação de factos sociais novos ou apenas diferentes. Neste ponto, Ragin chama a atenção para as duas componentes envolvidas na utilização das estruturas de análise: quando os pesquisadores usam os conceitos para classificar o fenómeno em estudo eles estruturam ideias por caso; quando usam os conceitos para caracterizar estes casos, eles estruturam ideias pelo aspecto.

48 A estruturação por caso, como acima se referiu, serve para identificar o objecto ou fenómeno e enquadra-lo de acordo com a sua natureza, e é comummente usada quer em pesquisas quer no dia-a-dia. A estruturação por aspecto envolve a especificação de características essenciais ou aspectos que diferenciam os casos dentro de uma mesma categoria; enquanto a primeira estabelece a categoria de um fenómeno, a segunda indica variação dos casos dentro dessa categoria, permitindo ao pesquisador ver o que está presente e o que está ausente num dado caso, o que, muitas vezes, é mais explicativo, mas para isso o pesquisador deve estar prevenido acerca da tendência geral de focalizar apenas no que está presente.

49 As evidências colhidas da vida social são um complemento fundamental dos dados colectados para a análise de um determinado fenómeno; para além das informações fornecidas por questionários e estatísticas, os pesquisadores recorrem quase sempre à anotação sobre comportamentos, actos, confidências, discursos ou descrições de circunstâncias semelhantes às que caracterizam o seu objecto de estudo. Para que essa recolha de informação seja efectiva e adequada, ele precisa seleccionar as mais significativas para os seus propósitos, recorrendo ao seu stock de estruturas analíticas para essa selecção.

50 Segundo Ragin, a necessidade de selecção coloca um problema: buscando seleccionar o material que mais interessa para a explicação do seu objecto de pesquisa, ele pode ignorar ou desprezar informações que coloquem em causa o ponto de vista que 
pretende defender; outras vezes, a ocorrência deste problema é motivada pela falta de recursos de conhecimento ou outros, tornando-se não-intencional, mas provocando os mesmos resultados: uma análise parcial. As consequências da influência ou da ignorância - parcialidade na análise -, nem sempre presentes na consciência dos pesquisadores, são muitas vezes evitadas pelo facto de a pesquisa social ser comunitária, ou seja, ela é objecto de análise pelos pares; mais do que nenhuma outra, a pesquisa social é sujeita a escrutínio antes de ser publicada o que, de certa forma, limita tais consequências; contudo, se o défice de informação ou a ignorância das potenciais influências são partilhados pela comunidade científica, não serão identificadas nessa etapa de escrutínio e as consequências não serão evitadas.

51 A síntese das evidências recolhidas leva o pesquisador à construção de imagens que implicam motivos e dizem algo a respeito das causas. Elas são construídas com o intuito de dar sentido às evidências, sumariza-las e relaciona-las com as ideias iniciais que motivaram a colecta de informações e dados. A intenção do pesquisador ao construir estas imagens é a de apresentar construções coerentes, que podem confirmar ou não as ideias originais. Elas podem ser usadas para ilustrar três das suas qualidades mais importantes - são idealizações de casos reais, são explicativas (implicam ou incorporam explicações) e são guias para futuras pesquisas. Na primeira, apesar de serem necessariamente incompletas porque não podem representar toda a complexidade da vida real, são construídas com base em evidências e podem ser relacionadas com ideias teóricas expressas pelas estruturas de análise. No segundo caso, porque as explicações são geralmente causais, fornecem informações sobre o que as coisas são e porque são assim, e estabelecem relações entre fenómenos distintos; algumas palavras (palavras causais) têm o dom de especificar a razão das coisas que caracterizam. Quanto à terceira qualidade, as imagens sugerem novas questões e novos caminhos para a pesquisa, ajudando os pesquisadores a ver o que está em falta e orientando-os na análise mais sistematizada da vida social para desenvolver novas estruturas analíticas, principalmente quando as evidências colectadas e embutidas nas imagens construídas levam à rejeição das ideias iniciais ou do ponto de partida.

As representações da vida social são o resultado do diálogo entre ideias e evidências: através de um processo de interacção entre estruturas analíticas e ideias, vão sendo produzidas representações cada vez mais aperfeiçoadas e explicativas acerca do objectivo perseguido pelo pesquisador. Elas são limitadas no seu contexto explicativo ao objectivo do pesquisador e apesar de apresentadas como produtos acabados, resultam de um longo processo no decurso do qual muitas estruturas possíveis e muitas imagens potenciais são abandonadas. Como é muito difícil apresentar a vida social sem a explicar, a explicação dos fenómenos ou factos é que dá coerência à representação; este é um dos aspectos a ser considerado, havendo necessidade de preparar a apresentação dos resultados: selecção da audiência, escolhas do meio de apresentação - filme, texto com fotografias, representações teatrais, relatórios ou comunicações em revistas especializadas, etc. Em geral, os pesquisadores sociais tendem a escolher este último meio de apresentação dos resultados das suas pesquisas e a seleccionar, como audiência, os seus pares.

Relacionando processos e estratégias em pesquisa social, Ragin afirma que a natureza da interação entre imagens e estruturas analíticas, existente em todas as pesquisas, determina o tipo de pesquisa, ou seja, a maior ou menor flexibilidade das estruturas analíticas utilizadas. Segundo ele, pesquisas há que partem de uma estrutura analítica 
rígida, definida à partida, como acontece no caso das pesquisas para testar teorias existentes; quando as evidências colectadas dão lugar a imagens que contradizem a hipótese formulada, esta é rejeitada. Elas são mais utilizadas em estudos quantitativos de co-variação. Noutros casos a estrutura analítica é construída à medida que a pesquisa progride, com recurso às evidências colectadas. A estrutura analítica inicial é flexível e serve como guia para a execução das primeiras etapas do estudo, sendo revista e reformulada sempre que as evidências colhidas a isso aconselham. Este tipo de estruturas é comum em estudos comparativos de diversidade. Existe ainda um outro tipo de estrutura analítica, que Ragin designa de fluida, muito comum em estudos qualitativos: existem à partida diversas estruturas analíticas possíveis, fornecendo cada uma delas os elementos de análise mais apropriados para evitar influências de ideias pré-existentes; à medida que as evidências colhidas e as potencialidades das diferentes estruturas disponíveis são avaliadas, há um processo de selecção e de construção de uma estrutura que corresponda aos objectivos da pesquisa. Contudo, em alguns casos, não só são mantidos os diversos pontos de partida analíticos, como constam do relatório final, incorporados numa representação final, como painéis.

Para Ragin o desafio que se apresenta à pesquisa social é o de construir representações fortes e instrutivas da vida social, que contribuam para a teoria social e que incluam, de forma sistemática, a maior quantidade e melhor qualidade de evidências da vida social, o que é alcançável através da construção de um diálogo entre ideias e evidências no processo de pesquisa social.

\section{Parte II}

\section{Capítulo 4 - Métodos qualitativos para o estudo das comunalidades}

O método qualitativo situa-se num dos extremos do compromisso existente entre o número de casos e o número de características distintivas dos casos, onde em poucos casos se estudam inúmeras características comuns, resultando numa maior clarificação de conceitos e de categorias. É o escolhido quando os pesquisadores acreditam que para produzir uma representação adequada o melhor caminho é o estudo detalhado de um fenómeno ou caso específico. Muito conhecimento pode ser acumulado através de entrevistas ou estudos de caso, histórias de vida ou de organizações. Na abordagem qualitativa o pesquisador deve definir qual a informação útil para o alcance do seu objectivo, num processo de crescente selectividade em função do aumento do seu próprio conhecimento sobre o seu caso, pelo refinamento e elaboração de imagens relacionadas com a pesquisa e da sua confrontação com estruturas analíticas. As imagens emergentes permitem estruturar as etapas seguintes da pesquisa, indicando novos caminhos na colecta de informações e abandonando outros. Contudo, trata-se de um processo interactivo entre as imagens criadas pelo pesquisador e os conceitos que orientam a pesquisa, no qual ambos se clarificam mutuamente, pelo confronto das evidências com as ideias articuladas pelas estruturas analíticas. Os conceitos resultantes deste refinamento são salientados na representação dos resultados da pesquisa.

56 Os principais objectivos da análise qualitativa são: «dar voz» a grupos marginalizados da sociedade, grupos que os pesquisadores acreditam tenham sido sub-representados ou 
não representados de todo; interpretar, histórica e culturalmente, fenómenos importantes para a compreensão de uma sociedade ou de uma nação (por exemplo, a escravatura; o autor apresenta um exemplo relacionado com a história dos Estados Unidos da América (EUA) em meados do século XIX), com o objectivo de ajudar a reinterpretar acontecimentos históricos importantes, pelo cuidado nos detalhes históricos; fazer progredir as teorias seja pelo conhecimento profundo de um caso e os elementos de análise que ele fornece, pela clarificação dos conceitos que ele provoca no decurso da realização da pesquisa, necessária para a selecção da informação e determinação dos passos seguintes, e pelo facto de realçar os aspectos comuns em diversos casos, o que resulta de uma análise multifacetada dos casos e das novas ideias que ela produz.

De uma forma geral, a pesquisa qualitativa parece menos estruturada do que outros tipos de estudos sociais, devido à abertura do pesquisador em relação ao assunto da pesquisa e ao seu desenrolar; o pesquisador dá preferência ao estudo de um caso ou de categorias de um caso e a desenvolver ideias a partir daí, construindo progressivamente a sua estrutura analítica. A escolha dos locais e dos casos depende dos objectivos que o pesquisador tem em vista, nuns casos com a preocupação de que sejam representativos - quando trabalham com um pequeno número de casos e pretendem, a partir deles, deduzir aspectos comuns - e noutros que sejam atípicos, fora do comum representando uma oportunidade para a geração de novas ideias.

o estudo de instâncias diversas no âmbito de um mesmo caso ou fenómeno permite aprofundar o conhecimento e produzir uma representação mais adequada; nestes casos, o alcance do ponto de saturação, ou seja, o momento a partir do qual as evidências recolhidas não acrescentam conhecimento ao pesquisador, leva-o a tomar novos rumos na colecta de informações ou considerar que tem os elementos necessários para a análise: quanto maior o conhecimento que o pesquisador acumulou sobre o seu caso, maior facilidade ele terá em tomar a decisão mais adequada nesse momento. Outro aspecto interessante neste tipo de estudos é o facto de o pesquisador descrever o seu caso como «singular», porque ele estuda as diversas instâncias em busca de um aspecto comum, o qual é salientado na sua representação. Ragin salienta que esta particularidade da análise qualitativa torna-se mais evidente quando comparada com a análise quantitativa, na qual os pesquisadores enfatizam as diferenças sistemáticas do estudo de muitos casos. Para o pesquisador em análise qualitativa, o número de casos não é a questão relevante, mas sim a fundamentação e a adequação da representação do seu caso.

Para além da selecção do assunto a ser estudado, outro aspecto importante é o recurso a conceitos que possam guiar a condução da pesquisa, embora possam ser refinados ou descartados no decurso da sua realização, dando lugar a novos conceitos que melhor direccionem a pesquisa para evidências mais relevantes.

Esta clarificação dos conceitos (componentes-chave das estruturas analíticas) está intimamente ligada à clarificação das categorias empíricas (que agrupam as características similares dos fenómenos sociais): os conceitos definem categorias e os membros de uma categoria exemplificam ou ilustram os conceitos que os unem numa mesma categoria. Os pesquisadores desenvolvem conceitos a partir das imagens que emergem das categorias dos fenómenos em análise.

61 Por sua vez, este processo conduz a uma maior elaboração das estruturas analíticas, flexíveis ou fluidas à partida, à medida que o conhecimento sobre os casos e as 
categorias se acumula, embora nem todos os pesquisadores em análise qualitativa se preocupem com a construção de estruturas analíticas, considerando que os seus casos são, por si sós, ilustrativos, deixando a outros pesquisadores a tarefa de construir estruturas analíticas. Esta relutância é interpretada como «não científica», decorrente de um interesse meramente descritivo; contudo, Ragin chama a atenção para o facto de que as pesquisas qualitativas apresentarem representações teoricamente estruturadas da vida social, que são resultado da interaç̧ão entre conceitos e imagens, independentemente dessa interacção ter sido explicitada pelos pesquisadores.

Os métodos qualitativos são geralmente identificados com observação directa dos participantes, entrevistas, trabalho de campo e estudos etnográficos, enfatizando a característica de imersão do pesquisador no ambiente da pesquisa e o esforço em descobrir o sentido e o significado dos fenómenos sociais para as pessoas desse ambiente, numa perspectiva que defende que a adequação dos resultados depende da capacidade do pesquisador em observar os fenómenos segundo a óptica das pessoas envolvidas no estudo. Contudo, quando o objecto da pesquisa é um acontecimento histórico, esta abordagem não é possível: nestes casos, o pesquisador procura juntar o maior número de evidências a partir das quais possa construir imagens significativas, com ajuda dos conceitos e das estruturas analíticas.

Uma das características comuns aos métodos qualitativos é a de que eles são condensadores de dados - eles condensam dados para produzir imagens, embora uma das características mais notáveis seja a de potenciarem os dados, reforçando o seu poder interpretativo e permitindo ver aquilo que antes não aparecia. Os procedimentos que tornam estas características visíveis são a indução analítica e a amostragem teórica.

64 A indução analítica pode ser entendida de diversas formas por diversos autores, mas Ragin considera que ela é uma estratégia de pesquisa que orienta os investigadores a prestarem atenção às evidências que desafiam, ou não confirmam, as imagens que eles estão desenvolvendo, porque elas fornecem as ideias-chave de como alterar conceitos ou modificar categorias. Esta técnica baseia-se na busca de similitudes nas várias instâncias da categoria, relacionando-as por forma a refinar a imagem; caso não sejam encontradas semelhanças, ou a categoria em análise é demasiado ampla e heterogénea necessitando ser redefinida, ou o pesquisador necessita voltar a reflectir sobre as evidências e reconceptualizar possíveis semelhanças. Os casos negativos são excluídos com a redefinição da categoria, ou tornam-se o foco essencial quando o pesquisador tenta reconceptualizar os aspectos comuns e, por essa via, tornar compatíveis evidências contraditórias. Segundo Ragin esta é uma técnica que implica interaç̧ão entre indução e dedução, que ele designa de redução.

65 A amostragem teórica é o processo de escolha de novos ambientes ou casos de estudo que sirvam de comparação com os que já tenham sido estudados e aplica-se tanto ao estudo de grupos sociais quanto à análise de acontecimentos históricos. Esta escolha varia em função da natureza e objectivos da investigação, sendo muitas vezes determinada por questões que resultaram do primeiro caso estudado. Mais do que fazer amostragem de forma a capturar todas as possíveis variações, a amostragem teórica visa ajudar ao desenvolvimento dos conceitos e a aprofundar a compreensão dos conteúdos das pesquisas. A sua selecção é feita a partir das ideias desenvolvidas no primeiro ambiente de pesquisa e fornecem uma oportunidade de confirmar e aprofundar tais percepções; se a pesquisa no novo ambiente contradiz as expectativas 
produzidas no primeiro, então o pesquisador é compelido a desenvolver uma outra compreensão de como e porquê isso aconteceu. Por isso, esta técnica é muito importante para a construção de estruturas analíticas.

Segundo Ragin, esta é também uma técnica da triangulação de dados, ou seja, uma forma de usar peças de informação independentes para conseguir mais elementos de algo que só é parcialmente conhecido. Ela permite aprofundar o conhecimento e provocar avanços na teoria social, para além de oferecer uma oportunidade para construção de generalizações e aprofundar o conhecimento de objectos de pesquisa ao mesmo tempo.

O estudo de caso recorre a técnicas do tipo da indução analítica e é muito usado para análise de acontecimentos históricos; o pesquisador reúne factos relevantes para a estrutura analítica e avalia se eles podem ser colocados conjuntamente numa imagem que confirme a interpretação prévia; muitos não serão relevantes e outros não serão consistentes com a interpretação prévia. Aqui a estrutura analítica joga um importante papel, ao definir uns factos como relevantes e outros como não relevantes; o problema é ver se todos os factos que são relevantes confirmam, ou são consistentes, com a interpretação feita; nesta perspectiva, os diferentes factos no estudo de caso são como as diferentes instâncias na indução analítica.

68 A interacção entre a interpretação do pesquisador e os factos pode levar a pesquisa a progredir ou, pelo contrário, conduzir a uma estagnação; em geral, esta interacção conduz a um refinamento tanto das ideias teóricas quanto das estruturas analíticas.

\section{Capítulo 5 - Métodos comparativos para estudar diversidade}

69 O que distingue a abordagem comparativa, apesar dos diversos métodos a que recorre, é o facto de privilegiar o estudo da diversidade. Os métodos comparativos permitem examinar padrões de semelhanças e de diferenças num número não muito grande de casos; a limitação de casos deve-se à preocupação dos pesquisadores em estabelecerem familiaridade com cada caso incluído na pesquisa. Para eles é importante saber como as diferentes partes de cada caso se combinam. Enquanto nos métodos qualitativos a ênfase nos aspectos comuns implica uma progressiva clarificação dos conceitos e categorias, nos métodos comparativos sobre diversidade, a categoria dos fenómenos em estudo é especificada no início da pesquisa e o objectivo do pesquisador é explicar a diversidade dentro de um conjunto particular de casos.

70 Na pesquisa que enfatiza a diversidade, o foco consiste nas semelhanças dentro de uma categoria de casos com o mesmo resultado, o que distingue essa categoria das demais e explica o resultado apresentado pela categoria. A maior diferença entre os métodos qualitativos e os métodos comparativos reside na diferença de orientação em relação aos casos; enquanto a pesquisa qualitativa estuda os aspectos comuns recorrendo a diversos casos com muitas instâncias do mesmo fenómeno, as pesquisas comparativas tendem a olhar as diferenças entre os seus casos. A pesquisa quantitativa também examina as diferenças entre casos, mas de um outro ângulo: o seu objectivo é explicar a co-variação de uma variável em relação a outra, recorrendo a muitos casos. Por essa razão, e em contraste com a análise comparativa, a pesquisa quantitativa estabelece pouca ou nenhuma familiaridade com os casos em estudo. 
71 O objectivo típico dos estudos comparados é o de separar as diferentes condições causais relacionadas com diferentes resultados: padrões causais que separam os casos em diferentes sub-grupos. Os objectivos dos estudos comparados são: exploração da diversidade, interpretação da importância histórica ou cultural, ou o avanço da teoria. Um resultado comum dos estudos comparados é demonstrar que casos que hajam sido definidos de início como «o mesmo caso», podem ser diferenciados em duas ou mais categorias na fase final do estudo.

Uma pesquisa comparada pode começar com uma tentativa de delineação de tipos, categorizando os casos de acordo com os seus diferentes resultados. Neste caso, o objectivo da pesquisa é separar as condições causais que geram resultados diferentes. Se, no decurso da pesquisa, são encontradas diferentes causas para diferentes resultados, é confirmada a interpretação inicial do pesquisador acerca dos factores que distinguem esses casos; caso contrário, será necessário reformular a estrutura da pesquisa. Este objectivo de explorar a diversidade é importante porque as pessoas, e os cientistas também, têm frequentemente dificuldades em ver as árvores da floresta, assumindo uma homogeneidade e uma generalidade onde na realidade prevalece a diversidade.

73 A pesquisa comparada começa com categorias de análise bem definidas; este foco torna as estratégias comparadas muito adequadas à interpretação histórica e cultural dos fenómenos relevantes recorrendo a um número não muito elevado de casos. Como a sua abordagem focaliza as diferenças entre casos e a diferenciação de tipos, facilita a interpretação histórica. Um exemplo apresentado por Ragin é o estudo das revoluções ao longo da história da humanidade e dos seus efeitos nas respectivas sociedades. A este propósito, o autor lembra que os movimentos massivos de sociedades orientados para a mudança social, são designados pelos cientistas sociais de «revoluções sociais» para os distinguir de outros tipos de revoluções que apenas visam uma rotação de lideranças ou de arranjos políticos.

Quando se consegue especificar um conjunto de casos comparados, estes casos contribuem para a interpretação e compreensão do novo caso (uma outra categoria construída para melhor ajudar a explicar os casos em estudo), porque o processo de classificação dos eventos em categorias produz elementos que facilitam a interpretação histórica.

A contribuição dos métodos comparativos para o avanço da teoria explica-se pelas suas próprias características, que são: o recurso a estruturas analíticas flexíveis, o foco explícito na diversidade, e a ênfase na análise sistemática das semelhanças e das diferenças e na especificação do padrão dessa diferença e da sua causa. Em geral, estes estudos apresentam uma estrutura analítica inicial específica, embora flexível, sujeita a revisão, esperando-se como resultado o enriquecimento e melhor definição das ideias iniciais em resposta às evidências colectadas durante a pesquisa; este processo permite refinar as ideias e as perspectivas teóricas existentes.

No decurso da pesquisa, os pesquisadores dedicados a estudos comparados colocam maior ênfase na causalidade e na complexidade causal do que os pesquisadores da análise qualitativa. Este é um aspecto central para a teoria social, uma vez que a busca por explicações dos «como» e dos «porquê» constitui uma característica distintiva das ciências sociais em geral. Para chegar à causalidade, os cientistas estudam os padrões de diversidade através da comparação de casos, que são vistos como uma combinação 
de características, examinando as semelhanças e as diferenças em combinações de características nos diversos casos.

O processo dos estudos comparados não se apresenta tão fluido quanto o do método qualitativo, nem tão rígido quanto o do quantitativo; começa com uma categoria de fenómenos cuidadosamente especificada e recorre a estruturas analíticas que contribuem para dar sentido à categoria seleccionada, e que estão sujeitas a revisão com base nas evidências. $O$ seu foco reside nos padrões de semelhanças e diferenças entre os casos e os padrões dessa diversidade, o que fornece matéria de revisão para a estrutura analítica inicial, e que resulta de um diálogo entre ideias e evidências que permite ao pesquisador a construção das representações sobre o assunto da sua pesquisa.

78 A selecção de casos obedece a dois critérios essenciais: que possam ser comparados (ou seja, que pertençam à mesma categoria) e que possam ser classificados em categorias significativas empiricamente definidas. O grau de pertença dos casos selecionados a uma mesma categoria é avaliado no decurso da pesquisa, num processo de selecção que pode levar o pesquisador a reformular a categoria.

O recurso a estruturas de análise a partir da literatura existente, acompanha em geral o processo de selecção dos casos; em situações menos frequentes, quando os pesquisadores estão interessados em mais do que uma faceta dos seus casos, apenas desenvolvem a estrutura analítica quando se sentem de posse de mais evidências significativas para o seu estudo. Também pode acontecer que, em alguns casos, desenvolvam estruturas analíticas a partir das evidências, mas estes são casos muito raros em estudos comparados.

o estudo da diversidade acompanha o estudo da causalidade, esperando-se que diferentes condições causais se relacionem a resultados diferentes, ou seja, o objectivo do pesquisador ao examinar as semelhanças e as diferenças é o de identificar ligações de causalidade, como diferentes configurações de causas produzem resultados diferentes nos diversos casos em estudo. A especificação de diferentes padrões de causalidade é a base principal da diferenciação de tipos: se causas e resultados não podem ser relacionados de maneira compreensível, o pesquisador deve reexaminar as suas especificações de causas e resultados e a respectiva diferenciação de tipos.

81 Os métodos comparativos são usados para estudar configurações, combinações específicas de atributos comuns a um certo número de casos. O exame de padrões de diversidade envolve, essencialmente, a busca de combinações de condições que distinguem as categorias dos casos.

82 As principais características da análise comparativa são as seguintes: 1) progride pela comparação de configurações de causas e não através da análise da presença ou ausência de cada condição causal ou do resultado; 2) admite que possam existir diversas combinações de condições gerando os mesmos resultados gerais; 3) pode visar padrões de causalidade complexos e aparentemente contraditórios; 4) pode eliminar causas irrelevantes.

$\mathrm{Na}$ análise comparativa cada caso é entendido como uma combinação de condições causais que produzem um determinado resultado; por isso, a selecção do resultado a ser estudado e a respectiva especificação causal, são passos fundamentais para o progresso da análise. Aqui, é fundamental não apenas o conhecimento que o pesquisador tenha do seu caso, mas também um conhecimento profundo da literatura existente, que lhe 
permitam especificar a natureza do resultado a ser estudado e a especificação de causas relevantes. Para a representação dos casos como configuração de causas, os cientistas sociais recorrem ao que designam de «presença ou ausência de dicotomias», o que significa que condições causais e resultados estejam ambos presentes ou ausentes em cada caso e possam ser codificados pelas palavras «sim» ou «não»: o número de condições causais determina o número das suas combinações possíveis, ou seja, a especificação de quatro condições causais permite 16 combinações possíveis (2 elevado à quarta). Quando as condições causais tiverem sido seleccionadas, são examinados os casos de acordo com cada combinação de condições causais: a existência de muitas combinações em que as causas não confirmam os resultados, deve ser entendida pelo pesquisador como um sinal de que a especificação das condições causais está incorrecta ou incompleta e deverá, tentativamente, corrigi-la.

Obtido um conjunto satisfatório de condições causais para um dado resultado, as evidências colectadas são representadas através de uma tabela designada de "Tabela Verdadeira»: nas colunas as combinações de condições causais ou de resultados, o número 1 indica a presença e 0 indica a ausência da condição. Nas linhas são colocados os resultados colectados, como acima indicado. Esta tabela costuma ser simplificada, utilizando configurações que identificam padrões, da seguinte forma: se duas linhas da Tabela Verdadeira diferem apenas em uma condição causal e apresentam, ainda assim, o mesmo resultado, então a condição causal que distingue as duas linhas pode ser considerada irrelevante e pode ser removida para permitir uma combinação mais simples das condições casuais. Este processo de combinação de linhas para criar termos mais simples pode ser realizado até que não haja mais linhas a remover, após o que se deve examinar a cobertura dos termos simplificados para ver se existem «sobras», termos que, por serem redundantes e não acrescentarem nada à descrição das combinações relacionadas com os resultados, devem ser eliminados.

Para a interpretação da tabela, costumam ser usadas grafias que facilitam a tradução da leitura dos números 1 e 0: escreve-se a condição presente com letras maiúsculas (por exemplo RAÇA) e a condição ausente (por exemplo eleições) com letras minúsculas. A primeira palavra indica a presença de diversidade racial, por exemplo, e a segunda indica a ausência de eleições, de jogo democrático.

A construção da Tabela Verdadeira é, em si, uma parte importante do diálogo entre ideias e evidências porque a tabela deverá ficar livre de inconsistências antes que possa ser simplificada; da sua simplificação emergem imagens baseadas em evidências, sob a forma de configurações de condições que diferenciam sub-conjuntos de casos.

\section{Capítulo 6 - Métodos quantitativos para estudar a relação entre variáveis (co-variação)}

87 A análise quantitativa parte do princípio de que o melhor caminho para a compreensão dos padrões básicos e das relações é o exame dos fenómenos em inúmeros casos: assim, torna-se possível avaliar as peculiaridades dos casos singulares e construir imagens da vida social livres de fenómenos específicos de um caso ou de um pequeno número de casos; o que importa são os padrões gerais.

Os pesquisadores em análise quantitativa constroem imagens mostrando a co-variação entre duas ou mais características ou atributos em muitos casos; elas são consideradas 
gerais porque condensam evidências de muitos casos: quanto maior o número de casos estudados, mais geral será o padrão. Eles sacrificam o conhecimento profundo de cada caso individual para obter um entendimento de padrões mais amplos de co-variação em inúmeros casos. O termo correlação descreve um padrão de co-variação entre duas variáveis mensuráveis; o termo por vezes é descrito como uma relação entre duas variáveis, havendo aqui que distinguir este tipo de relação entre variáveis (que implica a influência de uma na outra) com a relação entre actores sociais. Os atributos dos casos em estudo recebem o nome de variáveis porque eles são fenómenos que variam de nível e de grau: as causas dos fenómenos são definidas como «variáveis independentes», são os factores usados para explicar a variação das "variáveis dependentes», que são os efeitos ou resultados que o investigador pretende explicar. Esta classificação varia de caso para caso, ou seja, uma variável tida como independente pode aparecer como variável dependente num outro caso.

Os objectivos da pesquisa quantitativa são três: identificar padrões gerais e relações, testar teorias e fazer previsões. Todos eles implicam a análise de inúmeros casos e favorecem o diálogo entre ideias e evidências centrados nas ligações entre os atributos dos casos (variáveis) entre si.

90 A identificação de padrões gerais, ou seja, associações entre dois ou mais fenómenos em muitos casos, é importante porque eles fornecem importantes ideias-chave sobre causalidade, na medida em que a observação sistemática do relacionamento entre variáveis sugere a possibilidade de que uma delas seja condição causal da outra, ou que ambas sejam resultado de uma terceira variável não identificada. Estas relações causais por detrás das correlações são centrais nas representações sociais produzidas pela pesquisa quantitativa e são entendidas pelos pesquisadores como «explicações», uma vez que consideram que quando um caso é identificado, ele é explicado.

91 A marcha desta análise obedece, em geral, aos seguintes passos: identificação de um padrão de co-variação e avaliação da intensidade da correlação; inferência da causalidade a partir dessa correlação, e, em caso afirmativo, construção de uma explicação a partir da relação causal inferida. Em resumo, a construção das imagens na análise quantitativa parte do exame dos padrões de co-variação entre variáveis e infere causalidade a partir desses padrões gerais.

92 A abordagem quantitativa é muito útil para testar ideias teóricas e imagens gerais porque são relevantes para inúmeros casos - e parcimoniosas, porque dizem respeito à operação de apenas algumas, poucas, variáveis causais. Testar ideias significa usá-las para construir uma imagem teórica a partir da qual são derivadas hipóteses (proposições a serem testadas) acerca de evidências que ainda não foram examinadas; uma vez examinadas estas evidências, elas confirmarão ou não as hipóteses formuladas. A rejeição de uma hipótese conduz, em geral, a um caminho de elaboração de novas ideias teóricas, uma vez que uma ideia que seja sistematicamente rejeitada acaba por ser retirada do stock de conhecimento científico e substituída por novas ideias; as que resistem ao escrutínio são retidas.

93 A elaboração de previsões exige a análise de inúmeros e variados casos: muitas evidências sobre o comportamento das variáveis em estudo permitem ao pesquisador a formulação de previsões, o que é também facilitado pela acumulação de conhecimento sobre os padrões gerais, pelo facto de fornecerem ideias-chave sobre como avaliar a importância dos factores mesmo perante algumas incertezas e algum desconhecimento sobre o assunto em estudo. 
94 As imagens construídas pela pesquisa quantitativa são baseadas nos padrões gerais de variação em inúmeros casos e ligam a variação de um dos atributos do caso à variação de outros atributos; estes padrões de variação entre duas ou mais variáveis em muitos casos fornecem a matéria prima para a construção de imagens gerais, contrariamente às imagens detalhadas e profundas da análise qualitativa, construídas a partir do estudo de poucos casos. Ou seja, a estratégia quantitativa favorece a generalidade - a partir da avaliação da intensidade da correlação das diferentes variáveis causais - e a parcimónia, pelo uso de poucas variáveis para explicar o mais possível. Estas duas características presentes na análise quantitativa não se encontram nem na análise qualitativa - estudo detalhado e profundo para descobrir subtilezas e pequenas variações em poucos casos -, nem nos estudos comparados - focalizando a diversidade, a configuração de semelhanças e diferenças num conjunto não muito grande de casos.

95 A estratégia comparativa, em lugar de focalizar a co-variação dos atributos, privilegia a análise das diversas formas de chegar aos resultados produzidos por essa co-variação. Por isso, ela abrange um número não muito elevado de casos e aproxima-se da análise qualitativa ao valorizar o conhecimento dos casos singulares. Por outro lado, o contraste entre estudos comparados e análise quantitativa resulta da diferença entre examinar padrões de diversidade em alguns casos e procurar, em inúmeros casos, variáveis que pareçam estar sistematicamente relacionadas umas com as outras.

Relativamente ao processo, a abordagem quantitativa é a mais estruturada das três estratégias de pesquisa, o que tem a ver, por um lado, com os seus objectivos acima apresentados; o facto de inúmeras pesquisas quantitativas procurarem testar as teorias leva a que os pesquisadores que as preparam, o façam de forma cautelosa, para evitar que à partida elas estejam condenadas ao fracasso. Por exemplo, devem evitar as influências por parte dos respondentes aos inquéritos para colecta de dados, e devem preparar devidamente os inquiridores de forma a que estes não induzam as respostas e que estejam familiarizados com o objecto da pesquisa. A ênfase em variáveis e suas relações implica uma definição clara, à partida, de quais os aspectos mais relevantes do caso que serão examinados como variáveis: a fixação dos casos e variáveis implica a sua fundamentação em estruturas analíticas sólidas, particularmente quando o objectivo é testar teorias. Uma vez traduzida a teoria numa estrutura analítica, é possível elaborar hipóteses sobre como se supõe que as variáveis se relacionem umas com as outras. Para a confirmação das hipóteses formuladas, o pesquisador pode recorrer à medição das variáveis relevantes e à colecta de dados, usando técnicas de correlação para avaliar os laços existentes entre elas. Segundo Ragin, estas estruturas analíticas podem ser mais ou menos fixas; quando a estrutura é fixa, as imagens construídas a partir das evidências são «constrangidas» por essa rigidez, uma vez que nesta abordagem as estruturas analíticas guiam a colecta de dados, orientam o pesquisador sobre quais as variáveis relevantes e que devem ser medidas; limitam o espaço de acção do pesquisador à estrutura analítica inicial. Os resultados obtidos ou confirmam ou rejeitam, sem espaço para interpretações.

97 A colecta de dados «determinada» pela estrutura analítica é entendida como o preenchimento da tabela de dados - matriz de dados - que tem nas colunas as características consideradas relevantes para a análise e nas linhas os dados colectados, espelhando a estrutura analítica da qual derivou. A recolha de dados pressupõe uma selecção criteriosa dos casos, as características mais relevantes e os sub-tipos dentro 
dos casos; em pesquisa quantitativa os casos são, frequentemente, unidades básicas como famílias, empresas, organizações, grupos ou mesmo países, dada a sua preferência pela construção de imagens gerais parcimoniosas, que reflictam padrões gerais.

A medição das variáveis é criteriosamente preparada uma vez que, mesmo nos casos mais simples, nem sempre é fácil de conseguir, para além de que, muitas vezes, é grande a controvérsia em torno dos seus resultados. A preocupação com a validade dos seus resultados leva os pesquisadores a verificar as correlacções entre medidas alternativas que, segundo as ideias que motivaram o estudo, deveriam variar: se o comportamento das características se correlaciona fortemente com a variável medida, o pesquisador encontrará justificação para a sua selecção enquanto variável explicativa do seu caso. Outra preocupação dos pesquisadores é a confiabilidade das suas medidas, que tem a ver com a quantidade de «acaso» ou contingência incorporada numa dada medida, devida à amostragem ou colecta de dados. Para aumentar a confiabilidade dos seus dados, os pesquisadores desenvolveram uma série de técnicas, como a de agrupar respostas a diversas questões relacionadas com o objecto do estudo, para obter uma medida mais confiável; ou desdobrar as perguntas relevantes para o objecto do estudo, que representem diversos aspectos ou ângulos, a partir dos quais obtenham respostas que, em conjunto, produzam resultados mais confiáveis. A medição é uma das mais difíceis e importantes tarefas que o pesquisador em análise quantitativa tem de realizar porque quase tudo depende de uma medição livre de erros, uma vez que, neste tipo de abordagem não há como ter a certeza dos motivos que fizeram com que uma correlacção supostamente forte, se apresente como fraca.

Quando o objectivo é o teste de teorias, a análise de correlacções percorre um longo caminho: após a elaboração da estrutura analítica a partir das ideias teóricas, a selecção dos (muitos) casos apropriados, a escolha da estratégia de amostragem e a medição, confiável, das diversas variáveis; se o objecto da pesquisa é o teste de teorias, seguir-seá a especificação das ideias contidas na hipótese a ser testada e das variáveis centrais para a sua explicação. A etapa seguinte compreende a colecta de dados e o preenchimento da matriz definida a partir da estrutura analítica, dos casos seleccionados e das medidas criadas. Como a questão fundamental, neste caso, é se as correlacções seguem, ou não, padrões consistentes com as ideias que motivaram o estudo, é preciso fazer essa avaliação, que pode envolver a correlacção entre uma variável independente e uma variável dependente, outras vezes implica a comparação das correlações de diversas variáveis independentes com uma ou mais variáveis dependentes, outras vezes, ainda, envolve a comparação da intensidade da correlacção em diversos ambientes ou espaços de tempo. Quando o teste inicial de uma hipótese falha, ou seja, os resultados obtidos não confirmam as ideias contidas na hipótese, o pesquisador volta a examinar as evidências colhidas para ver se existe alguma possibilidade de a sua teoria ser confirmada sob condições específicas, considerando que outros factores têm de ser considerados. Nestas situações, ocorre o recurso ao conhecimento acumulado pelo pesquisador em relação ao objecto de estudo e o seu entendimento teórico para antecipar os refinamentos necessários à sua hipótese, incluindo a formulação de hipóteses, alternativas ou adicionais, antes da colecta de dados.

100 Os métodos quantitativos centram-se nas relações entre variáveis, especialmente os efeitos das variáveis causais, ou independentes, no resultado, ou seja, nas variáveis dependentes: a intensidade da correlacção entre as variáveis independentes e 
dependentes fornece evidências que confirmam, ou não, a ideia inicial de que essas duas variáveis estão relacionadas de maneira causal ou interligadas de qualquer outra maneira. $\mathrm{O}$ grau exacto da correlacção entre duas variáveis pode ser determinado pelo cálculo do "coeficiente de correlacção», dos quais o mais conhecido é o coeficiente de Pearson: se a correlacção é substancial e a sequência causa versus efeito faz sentido, então a causa (variável independente) explica a variação do efeito (a variável dependente). A correlacção pode ser «positiva» - quando a alta intensidade da variável independente está associada a uma alta intensidade da variável dependente -, ou «negativa», no caso inverso. 0 coeficiente de correlaç̧ão permite ter uma avaliação quantitativa directa do grau de co-variação dos fenómenos nos diversos casos. A nãoexistência de uma correlacção prevista é um desafio às ideias geralmente aceites.

o cálculo dos coeficientes de correlacção é realizado, normalmente, através de programas computorizados, o que simplifica a sua determinação. Se não existe padrão de variação entre duas variáveis, não existe correlacção entre elas; a chave para o cálculo do coeficiente de correlacção é a conversão dos resultados das duas variáveis em escores Z (operação explicada pelo autor no anexo). Os valores $\mathrm{Z}$ padronizam as variáveis de forma que todas tenham a mesma média (0) e o mesmo grau de variação: o coeficiente de Pierson é a média dos produtos dos escores $\mathrm{Z}$ relativos às variáveis do estudo.

\section{Post-scriptum}

102 Escrito em colaboração com a esposa, Mary Driscoll, o autor passa em revista o argumento base do livro: apesar das diferenças entre as três principais abordagens das pesquisas sociais, existem muitos aspectos comuns entre elas: endereçam questões relevantes para as sociedades e as pessoas, permitem o teste e actualização das ideias teóricas, incorporam uma grande quantidade de evidências e todas envolvem processos de análise sistemática dessas evidências, cujo resultado é a produção de representações fundamentadas da vida social. A principal diferença entre as abordagens reside na forma de conseguir essa fundamentação. São diferentes formas de analisar e representar a vida social, em função dos objectivos que os pesquisadores têm em vista.

São também referidas as principais críticas endereçadas à pesquisa social, ressaltando as que reclamam que cada pessoa e cada situação são «únicas», devendo ser entendidas como tal. Para os autores do Post-Scriptum, o que se perde ao não estudar a individualidade de uma pessoa ou situação, ganha-se em representações mais amplas da vida social, as quais permitem identificar os entrelaçamentos sociais que trespassam os problemas individuais, mostrando quando eles são, de facto, tendências gerais. Ligando o individual com a sociedade, estendendo as circunstâncias individuais do dia-a-dia para o campo das questões sociais, os cientistas sociais ajudam a compreender o que está acontecendo no mundo e em si próprios. A vida individual ganha uma nova dimensão com o conhecimento da vida social; a pesquisa social dá destaque ao individual nas perspectivas histórica e cultural. A pesquisa social acrescenta conhecimento ao stock comum da sociedade e ajuda a compreender o sentido do mundo e dos processos e acontecimentos históricos. A pesquisa social é uma tarefa colaborativa que junta muitas pessoas com ideias e imagens distintas umas das outras e, por conseguinte, com diferentes representações, o que pode resultar na produção de inúmeras soluções para os nossos, muitos, problemas. 


\section{AUTOR}

\section{CESALTINA ABREU}

tinaabreu@yahoo.com.br tinaabreu@hotmail.com

Professora Auxiliar e Chefe do Departamento de Sociologia da Faculdade de Ciências Sociais (FCS)

da Universidade Agostinho Neto (UAN).

Doutorada em Sociologia (2006) e Mestre (2011) pelo Instituto Universitário de Pesquisas do Rio de Janeiro (IUPERJ), República Federativa do Brasil. É Licenciada em Agronomia (1977) pela Universidade de Luanda (curso superior de Agronomia, Huambo). A sua dissertação de mestrado intitula-se Participação faz diferença? Reflexões na avaliação do Fundo de Apoio Social (FAS) no Sudoeste de Angola (Huíla, Namibe e Kunene); e a tese de doutoramento tratou da Sociedade civil em Angola. Da realidade à utopia. Obteve o Certificado em estudos avançados em prática académica (CASAP), módulos 1 e 2, na Universidade de Newcastle (2013), Grã Bretanha. É actualmente Professora Auxiliar e Chefe do Departamento de Sociologia da Faculdade de Ciências Sociais (FCS) da Universidade Agostinho Neto (UAN) e docente convidada do Curso de Mestrado em Ordenamento e Planeamento de Áreas Urbanas do Departamento de Arquitectura da Faculdade de Engenharia da UAN. As suas áreas de interesse no âmbito da Sociologia Política envolvem questões multidimensionais da cidadania, análise de contexto, abordagens de desenvolvimento, sustentabilidade e ambiente, capital humano e social, participação, direitos humanos e justiça social, cultura cívica, espaço público e sociedade civil, memória social, confiança e tolerância. Publicou, entre outros, os materiais seguintes: a) em capítulo de livros: «Cidadania e participação em Angola. Que papel para a sociedade civil?», in Boaventura de Sousa Santos e José Octávio Van-Dúnem (orgs.), Sociedade e Estado em construção: desafios do direito e da democracia em Angola. Luanda e justiça: Pluralismo jurídico numa sociedade em transformação, volume I, Coimbra, Almedina e CES - Centro de Estudos Sociais da Universidade de Coimbra, 2011, pp. 369-403; «Angola, SADC e a globalização», in Jonuel Gonçalves (org.), Atlântico Sul XXI. América do Sul e África na virada do milénio. São Paulo, Editora Unesp, pp. 185-207; «A sociedade civil em Angola e seus desafios internos e externos», in Nuno Vidal e Justino Pinto de Andrade, Sociedade civil e política em Angola. Enquadramento regional e internacional. Prefácio de Patrick Chabal. Luanda e Lisboa, Edições Firmamento e Média XXI, 2008, pp. 101-114; b) artigos e comunicações em eventos científicos: «Globalização: da transformação do espaço social à oportunidade de mudança social», Mulemba - Revista Angolana de Ciências Sociais (Luanda), vol. IV, n. ${ }^{8}$, Novembro 2014, pp. 393-422; «Revisitando uma obra exemplar: Dialectic of enlightenment. Philosophical fragments, de Theodor Adorno \& Max Horkheimer», Mulemba - Revista Angolana de Ciências Sociais (Luanda), vol. IV, n.․ 8, Novembro 2014, pp. 641-658; «Concepções e práticas pedagógicas no ensino das ciências sociais e humanas", Mulemba - Revista Angolana de Ciências Sociais (Luanda), vol. IV, n. 7, Maio 2014 , pp. 291-306 (em parceria com Eugénio da Silva e Pedro Manuel Patacho); «Em busca da (re)organização da vida em Angola», comunicação ao I Colóquio da Faculdade de Ciências Sociais da Universidade Agostinho Neto, Luanda, 25-26 Outubro 2011, Mulemba - Revista Angolana de Ciências Sociais (Luanda), vol. II, n.. 3, Maio 2012, pp. 103-127; «Desigualdade social e pobreza: ontem, hoje e (que) amanhã?», RAS - Revista Angolana de Sociologia (Luanda), n. 9, Junho de 2012, pp. 93-111; «Pobreza em Angola: percepções, acção colectiva e os dilemas de participação com base numa pesquisa qualitativa», comunicação à I conferência internacional sobre Gestão das cidades, intervenção tecnológica e combate à pobreza, Luanda, 23-24 de Junho de 2011. 
Luanda, IMETRO — Instituto Superior Politécnico Metropolitano de Angola [actas não publicadas]. 